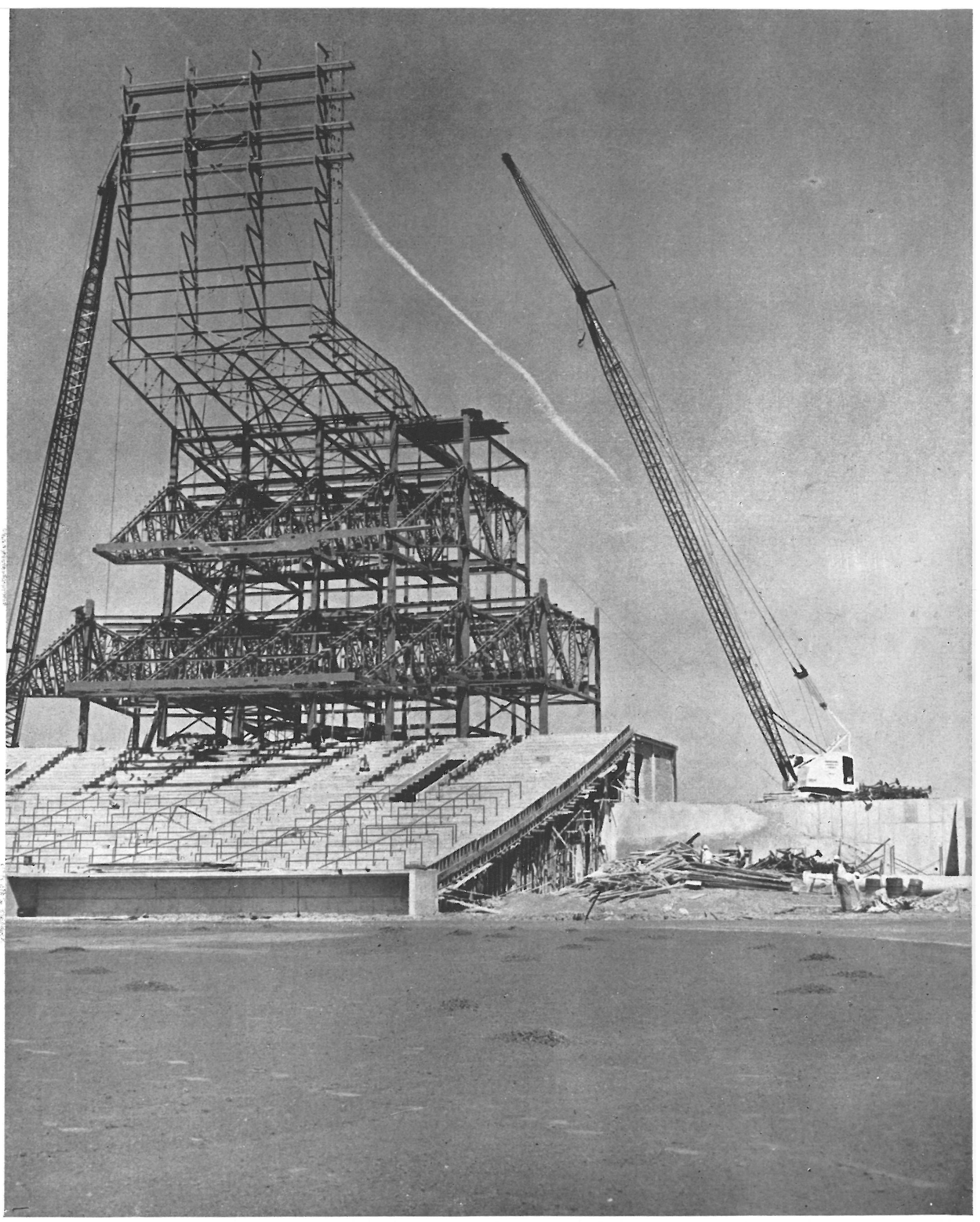

$841 \cdot 9$

\title{
estadio de Minneapolis
}

Información amablemente facilitada por la American Hoist and Derrick Company de Minnesota. 


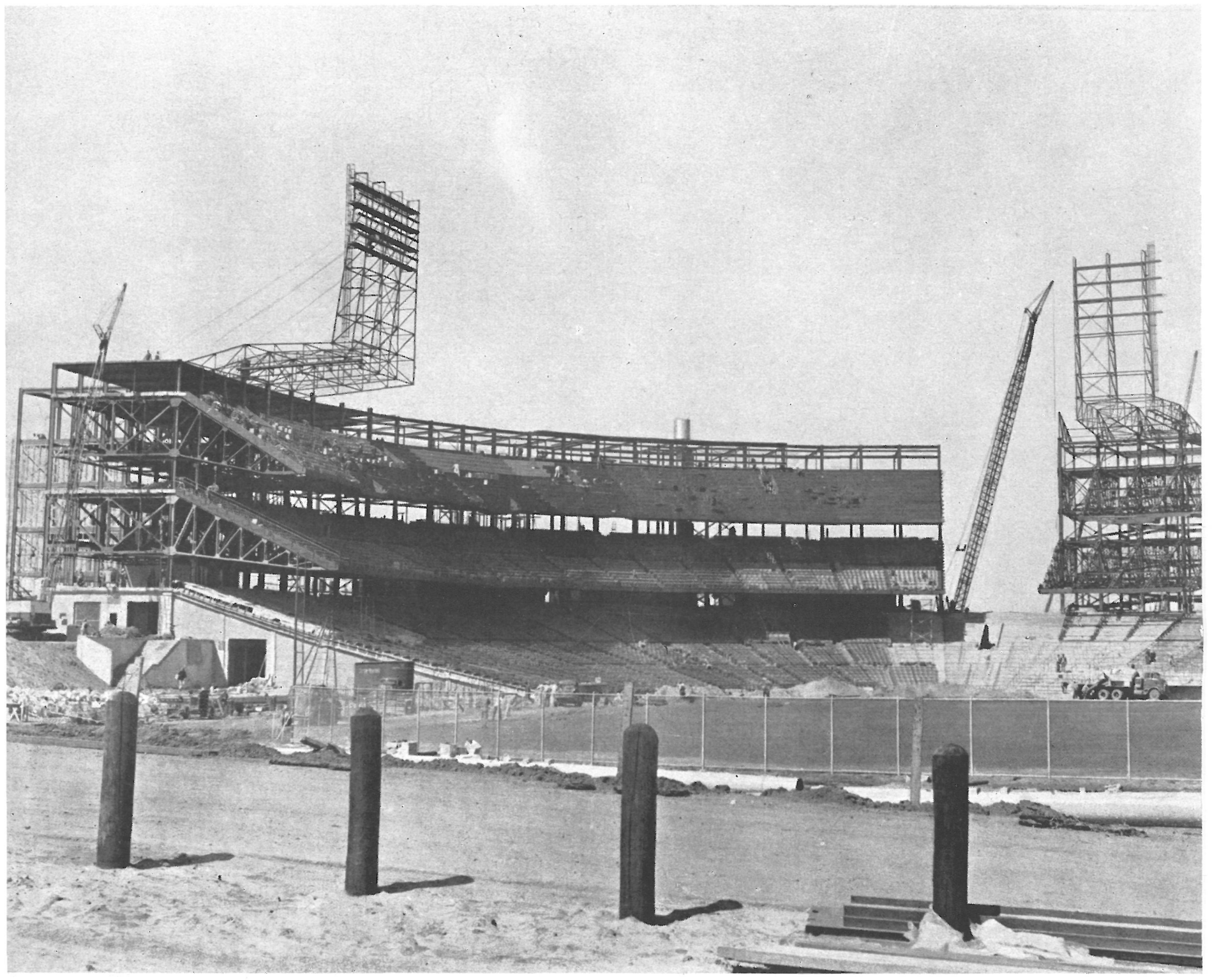

En Minneapolis, estado de Minnesota (EE. UU.), se ha construído un nuevo estadio dedicado al "baseball", que, por su capacidad y situación relativa, permitirá se puedan jugar en él competiciones de la mayor importancia, haciendo copartícipes de estas ventajas a los siete estados que le rodean, con los que Minneapolis formará parte en los campeonatos de esta especialidad.

La construcción de esta importante obra se ha podido llevar a cabo gracias a un gran esfuerzo financiero local.

Un graderío, de tres plantas, rodea parcialmente el terreno de juego. Este graderío, con los anexos, permitió acomodar, sentados, a unos 30.000 espectadores. Los dos anfiteatros superiores se proyectan en voladizo hacia el campo de juego, pero, como no tienen ninguna clase de soporte, la visibilidad es perfecta y carece de estorbos intermedios, como ocurriría al existir columnas. 


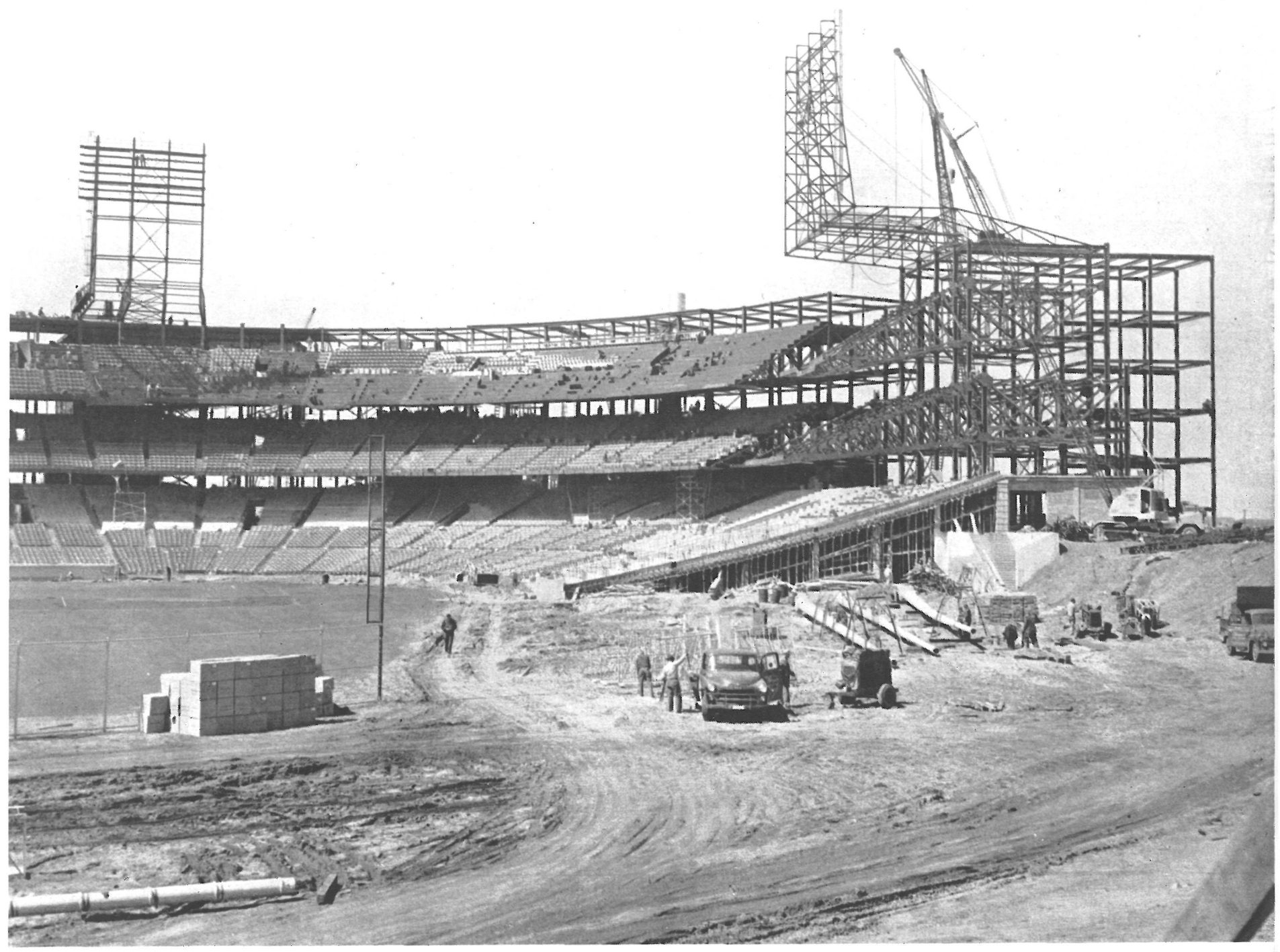

La estructura es metálica, convenientemente anclada en su parte posterior para poder absorber las grandes solicitaciones creadas por los graderíos que se apoyan sobre las ménsulas.

El entramado resistente que soporta los anfiteatros en voladizo forma un reticulado rectangular muy robusto, y las cerchas que constituyen las ménsulas se han reforzado con barras de triangulación en celosía.
Las dos pantallas metálicas-soportes de los proyectores que han de iluminar el estadio durante los partidos nocturnos-se han construído también en voladizo y están situadas en la parte superior del último anfiteatro, para, de esta forma, obtener un cruce apropiado de haces luminosos que permitirá una distribución uniforme de luz en el campo de juego. 


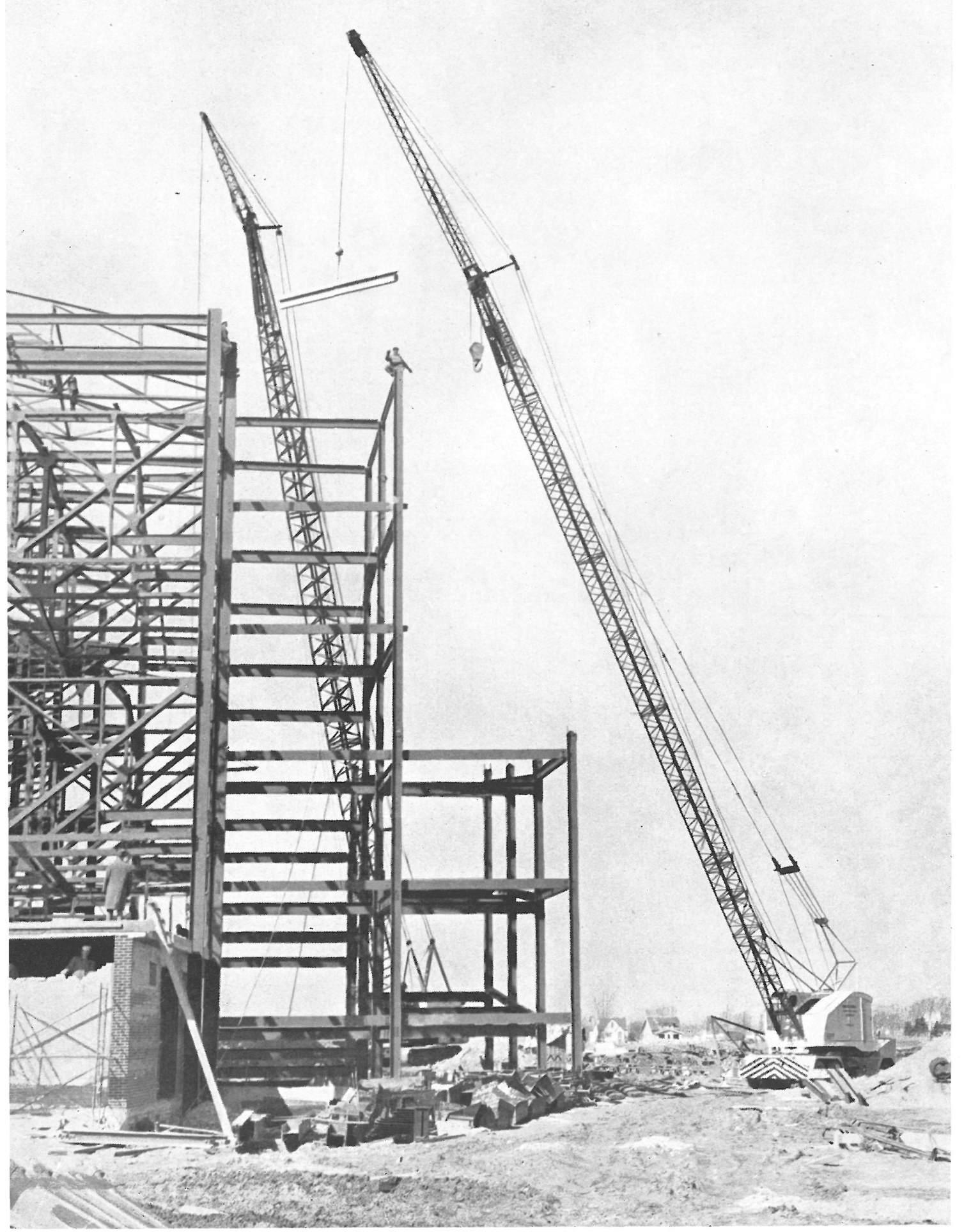

Disposición de la estructura que sirve de soporte a la instalación del sistema de ilumi-
nación artificial.

\section{construcción}

La construcción de esta obra se caracteriza por la gran rapidez desarrollada en la ejecución de trabajos. La particularidad más notable de los métodos constructivos empleados consiste en la utilización de grúas móviles, de gran capacidad, de la casa American Hoist. Uno de estos modelos, montado sobre orugas, tiene 30 toneladas de capacidad, y se ha equipado con una pluma de $30 \mathrm{~m}$ de longitud con un aguilón de $9 \mathrm{~m}$, lo que le da un gran radio de acción.

Los terrenos ocupados por el nuevo estadio son de gran extensión, ya que en el exterior se ha habilitado una gran zona para el estacionamiento de unos 15.000 vehículos.

J. J. U. 